Presumed Curable:

An Illustrated Casebook of Victorian Psychiatric Patients in Bethlem Hospital

Colin Gale, Robert Howard

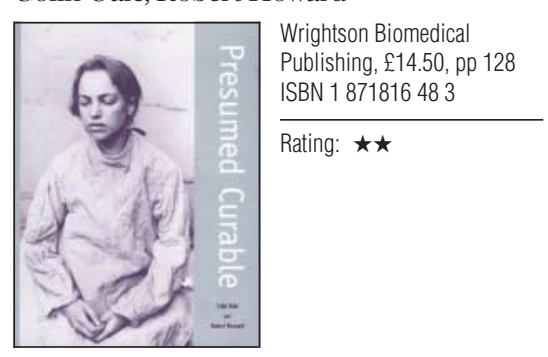

$\mathrm{B}$ ethlem is one of the most prestigious institutions in the history of psychiatry, its antecedents dating from the 13 th century. Between 1886 and 1895 some 300 photographs were taken of its inpatients. At that time, evolution and its ugly sister, eugenics, were on the rise, and one can only speculate on the purpose of these images (though they were probably used for teaching).
Sixty one of the patients featured in the book are identified by name, their photographs published along with extracts from their committal papers. From condensed summaries we learn the fate of eachapproximately a third left Bethlem "well.” All the identified patients had psychotic illnesses: mania and melancholia, general paresis, and post-encephalitic states. Schizophrenia had yet to be defined, although catatonia is described. These people were admitted if considered curable; they were discharged after a year if deemed unresponsive. They emanated from the middle class; the poor went elsewhere, to the county asylum, while the wealthy had private care.

Such a project throws up a number of questions. What do we expect to see in a book of such photographs? Staring eyes, torn clothes, drooling lips? Are we surprised if they appear unremarkable? Are we any the wiser if the photographs show ordinary people in everyday dress? And is being identified posthumously really a means by which one's "voice is heard" or "dignity accorded," as the authors suggest? Which of us would choose to be remembered in this way? Or, perhaps more appropriately, how would an "average" Victorian wish to be remembered? It is noticeable that 16 patients avert their gaze.
The case summaries serve to remind us how recent medical psychiatry really is and how treatments that we already take for granted have changed the medical landscape. Initially saddened by these fractured lives, I finished the text reflecting that we are mostly spared the severity of psychosis reported here. We take it for granted that any form of restraint is uncommon now, and if resort is made to "seclusion" then we monitor its use and restrict its length. But without the drugs we use we might still be living with violence and restraint, applied for months on end, with filth and padded clothing, and with all the residue of institutionalisation and concomitant physical decline. Although there is still much room for improvement, this text reminds us how bad things might otherwise be.

Nevertheless, do we need to see the photograph and to know the name? Who is restored in such a text: the people as they were before psychosis intervened or the inpatients shown here at their lowest ebb? Any voices that are heard belong to the latter, not the former, and any dignity accorded has come too late.

Sean A Spence reader in general adult psychiatry, University of Sheffield

S.A.Spence@Sheffield.ac.uk

\section{Evidence-Based Public Health}

Ross C Brownson, Elizabeth A Baker, Terry L Leet, Kathleen N Gillespie

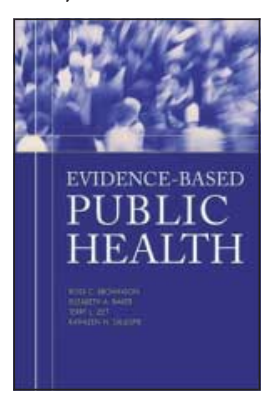

$$
\text { Oxford University Press, }
$$
$£ 29.50$, pp 235 ISBN 0195143760 Rating: $\star \star \star$ he preface of this book, which aims to describe how to implement evidence based public health interventions, sets high expectations. In it Jonathan Fielding, director of public health for the county of Los Angeles, states: "If every public health practitioner absorbed

Items reviewed are rated on a 4 star scale ( $4=$ excellent) and applied the key lessons from this volume, public health would enjoy a higher return on the tax payer's investment."

I was looking for a book that was grounded in the familiar territory of evidence based medicine much documented in the pages of the $B M J$ in recent years. I was not disappointed. I then looked for sensible application of this territory to public health practice and for an easily understood and systematic approach to making it happen. Again, I was pleased to see precisely this emerge.

The excellent opening chapter sets the structure for the rest of the book. The book's authors (all from the St Louis University School of Public Health) describe a simple adaptation of evidence based knowhow to form a six step public health guide:

- Develop an initial statement of the issue

- Quantify the issue

- Search the scientific literature and organise the information

- Develop and prioritise programme options

- Develop an action plan and implement interventions, and

- Evaluate the programme (then discontinue, remodel, or disseminate it widely).
Before dealing with the detail of these steps in the last six chapters the authors address two difficult subjects in chapters two and three. The first is how to decide when the time has come for public health action. The key issues they look at here include the reliability of evidence, the relation between cause and effect, and the wider influences on successful intervention in the community.

The second subject is how to use complex reports to inform policy decisions. The authors focus on systematic reviews, meta-analyses, decision analyses, and economic analyses and the "implementation" of findings through expert panels and guidelines. Although useful, the information in these two chapters would have been better integrated into the chapters dealing with the first three steps described above.

The rest of the book describes the details of the six steps. The descriptions are practical and illustrated with examples from the United States. The section on searching the scientific literature and organising information was particularly useful.

Phil Ayres deputy medical director and organisational development adviser, Leeds Teaching Hospitals phil.ayres@leedsth.nhs.uk 


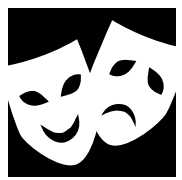

\section{Cancer Tales}

Written by Nell Dunn

Directed by Trevor Walker

Greenwood Theatre, Weston Street, London SE1, 16 May Performed as part of the Art of Dying symposium at King's College London

www.kcl.ac.uk/depsta/humanities/art_of_dying

Rating: $\star \star \star \star$

W

hen Nell Dunn's father died from cancer, she found it difficult to handle. She did not know how to help him or cope with his death. She lived in denial for years. That was 25 years ago. Now, at the age of 67 , she feels that she needs to learn from that experience and be "more friendly with death." She says: "I want it to be part of ordinary life."

Dunn decided to learn from others and write Cancer Tales. She got in touch with friends whose lives had been affected by cancer, friends of friends, and oncologists and their patients, and decided to tell their stories. Dunn calls them "love stories"-how people come together and cope in a crisis.

Five personal histories of pain, hopelessness, hope, resignation, and love are the ingredients for Cancer Tales. Full of feeling, this play sends out a message: that life is still life until the last moment and that patients who are approaching death need to be treated as living people. What makes the difference can be rather simple, but doctors often face the problem of overcrowded wards and practices, and being in the right place at the right time with the right words can sometimes be difficult.

These five real stories take us to real problems. The monologues and dialogues are brilliantly written, transporting the audience into the minds and the lives of the characters. The set is minimal, the play mesmerising.

Joan (played by Judy Wilson) watches her son dying from lung cancer. She is in denial about it. Another person in a similar situation might act differently. Rebecca (Paula Plantier), for example, is a young and independent woman who returns home with leukaemia after living abroad for many years. She starts again, learning to live with her family, to depend on others, and to search for dignity and individuality. Her relationship with her mother, Mary (Sheila Ruskin), is frustrating; Mary “just doesn't know how to be around Rebecca."

Marilyn (Di Sherlock) has a large, inoperable, uterine tumour. The unconditional love that her girlfriend, Penny (Nancy McClean), feels towards her shows how together people can become stronger, and how they learn to solve problems, to live during difficult moments, and, finally, to accept death.
Sharon (Nicola Goodchild) is a young woman with breast cancer. She isn't bothered about losing a breast but is devastated at the prospect of losing her hair. She and her husband work through each problem that the debilitating and devastating chemotherapy throws at them.

Clare (Laura Fitzpatrick), also a young woman with uterine cancer, is blunt and to the point about the small things that can make a difference. She feels invisible: "This huge thing takes over and the little things are lost-it makes a difference to be recognised." She describes the indignity of being treated with vaginal radiotherapy.

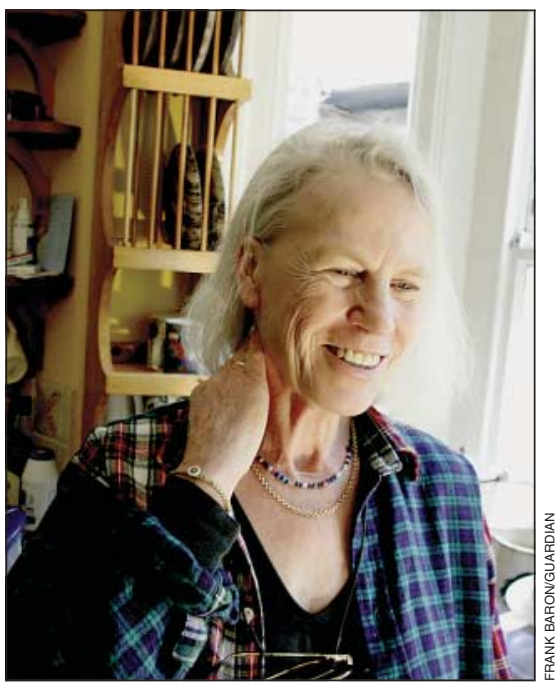

Dunn: now less afraid of death

In each of these stories there are incompetent doctors and the occasional nurse, saying the wrong thing and almost acting negligently. One of the themes is that patients and carers want doctors to be clear and perceptive. As well as being a powerful and moving drama, Cancer Tales is a lesson in communication skills and in dealing with patients. Several hospitals in the United States have approached Dunn asking her to run productions of the play for them.

Dunn believes that "acting is an unparalleled way to experience life from the other side" and she believes that she has learnt a great deal from Cancer Tales. She is less afraid of death and now feels able to ask for support and to give it. She has thought deeply about what makes a good death. As her play shows, it is different for each patient, but there are some things that everyone would like: autonomy, dignity, to be free from pain, and to be with loved ones. When Rebecca dies, she is pain free and surrounded by her family. "It's time to go now, mum," she says.

\section{Monica Desai fourth year medical student,} Imperial College, London, Adrian Gonzalez BMJ Clegg Scholar,

Nell Dunn's script of Cancer Tales is published by Amber Lane Press, priced £7.99. A BMJ theme issue on what is a good death is scheduled for 26 July 2003.

\section{NETLINES}

- The Perinatal Educational Programme aims to help health professionals in less well off areas who look after pregnant women and their offspring advance their own education (www.pepcourse.co.za). No teacher is necessary and educational materials are available online. Although the course was designed to address maternal and newborn care in South Africa, its authors say that the site would be useful in other developing countries and poor communities in developed countries.

- Australian Skeptics (www.skeptics. com.au) is a site that claims to investigate pseudo-science and the paranormal "from a responsible scientific viewpoint." It is a well produced resource with a lot of

content, including quizzes, news, links, and a media watch section. So what exactly is the site sceptical about? The list of subjects is long (www.skeptics.com.au/about/ overview.htm) and includes homoeopathy, human cloning, vitamin supplements, and near death experiences. The site says that it aims to "stimulate inquiry and the quest for truth, wherever it leads."

- Cancer Facts and Figures

(www.show.scot.nhs.uk/isd/cancer/ facts_figures/facts_figures.htm) is a fine collection of data from the NHS in Scotland's information and statistics division. It provides information about cancer incidence (up to 1999) and cancer mortality (up to 2001) in Scotland. The publishers have realised that in such a data dense environment the style and manner of presentation are important, and they have produced an elegant and easy to use site. Good use of colour and boxed topics make navigation easy and to start with there are a relatively small number of hypertext choices.

- The Infectious Diseases Society of America has produced a useful collection of links (www.idsociety.org/

Links_TOC.htm). While this includes plenty of US based organisations, there is also a link to an international section, which allows access to a wide variety of relevant resources subdivided by geographical region. This is an excellent gateway to a large volume of online material about infectious diseases.

- Whatever one's views about the threats posed by chemical and biological weapons, the Centre for Nonproliferation Studies at the Monterey Institute of International Studies has assembled an interesting page of resources on the subject (http://cns.miis.edu/research/ cbw/index.htm). Visitors can view its archive of material in date order or by geographical region.

Harry Brown general practitioner, Leeds DrHarry@dial.pipex.com

We welcome suggestions for websites to be included in future Netlines. Readers should contact Harry Brown at the above email address. 


\section{Promoting blood donation among British Muslims}

$\mathrm{I}$

$\mathrm{n}$ our experience, rates of blood donation among some black and other ethnic minority groups are currently very poor, increasing the difficulty of finding matched blood for people from these groups who need emergency transfusion. We have found that less than $2 \%$ of people attending blood donation sessions in the West Midlands-an area with a high proportion of people of Pakistani and Bangladeshi origin-were from ethnic minority communities.

The National Blood Transfusion Service is introducing a question on ethnic origin in its health check forms for donors. This development is to be welcomed, for at least two reasons. Such categorisation should make it easier to find blood for people who have rare blood types. And, with the implementation of the Race Relations (Amendment) Act 2000, for the first time there will be the means to monitor service delivery to ethnic minority groups, thereby providing some assessment of opportunities for people from these communities to donate blood. While we welcome this development we feel that in itself it is unlikely to promote blood donation in these communities. What is needed is far more insightful interventions that are informed by a working appreciation of the various barriers against blood donation.
Recently we began a campaign to promote blood donation among Walsall's large Muslim population. Through informal discussions with community leaders, elders, and members of the general public we have begun to identify at least some of the key conceptual and practical obstacles. The concern we most commonly encounter is an uncertainty as to whether or not blood donation is against the teachings of Islam. Other barriers included a lack of awareness of the existence of facilities for donation, the belief that being too old or taking medicines precluded eligibility to donate, and a fear of becoming infected while donating.

Central to our campaign has been a willingness to work with local communities and their representatives. We have estab-

lished a donor centre in a state of the art building in the heart of Walsall's Muslim community, and we have embarked on an education programme to dispel some of the myths concerning blood donation. With the help of imams of local mosques we have begun explaining the fluidity and in-built dynamism of Islamic law. Thus, while emphasising that life and our bodies are most certainly a sacred trust from God, we

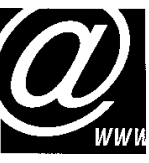

WEBSITE OF THE WEEK

Fabian Waechter $B M J$ fwaechter@ bmj.com
SARS revisited We last looked at internet coverage of severe acute respiratory syndrome (SARS) only four weeks ago (http://bmj.com/cgi/content/full/326/ $7395 / 937 / a)$. But since then readers have brought a number of other sites to our attention. With such a fast developing and ever changing subject as the SARS outbreak, the explosion of new sites is not surprising. This is one of the fundamental strengths of the internet, along with highly visible, fast updates, which are unattainable by the print media. But in the case of something like complex health information, the internet also has its weaknesses. One of these is the lack of "editorial" information about the sites that we surf.

Many of the sites on SARS that readers recommended look (and are) very good. It is another strength of the internet that it is not restricted to professional media people or international associations like the World Health Organization. Anybody can put up information. It might as well be you or me. Consequently there is an abundance of private pages about SARS and many of them offer a good selection of information and hyperlinks. However, only a few of them are explicit about the people or organisations behind them (whereas if you go to http://bmj.com/aboutsite you will soon know everything about us).

Sites such as www.sarsnewswire.com or www.urbaniSARS.com are very slick - they look great and contain a lot of useful and well selected information and resources about SARS. However, neither site tells us anything about the people who run them, why they produce them, and, no less important, where in the world they do so.

Another pitfall, especially for the uninitiated, is the false security of posh domain names. Rare visitors to the internet, perhaps driven by fear of SARS, might go for www.sars.com, a presumably reasonable choice. They will, however, find tabloid style information, funny or rather scary pictures, and definitely no information whatsoever of how, where, or why this important piece of human knowledge was created. And, most importantly, we do not learn who created it. I wonder why. have also been able to highlight how the preservation of life is a higher order objective (indeed, the Arabic term shar'iah means "the path leading to the well of life"). Hence we can explain that many Muslim jurists have ruled that in cases of need it is acceptable-indeed commendable-to donate blood.

On our inaugural day we were pleasantly surprised, with over 30 donations. Another 15 people who were willing to donate had to be turned away, however, because of recent visits to areas where malaria is endemic. As this was for many of them their first visit, this may unfortunately discourage further attendance.

Through talking to donors we have been able to better understand some of the practical strategies that could facilitate blood donation. For example, we have learnt about the importance of making it possible to donate in the late afternoon and at weekends-such times being better suited to the working patterns and lifestyle of people in this community. Some times, such as Fridays and the month of Ramadan, are inconvenient and should perhaps be avoided when planning donation sessions.

Most gratifying of all has been seeing a small but dedicated group of people become regular donors. We believe that by involving key stakeholders in strategic discussions, such as the development of suitable educational resources, many of the barriers to blood donation in this community can be overcome.

Certainly, our experiences suggest that by connecting with the populations they serve health providers can do much to promote health, wellbeing, and social inclusion, even among the most marginalised sections of our society.

Aziz Sheikh postdoctoral fellow, St George's Hospital Medical School, London

A R Gatrad consultant paediatrician,

Manor Hospital, Walsall

steadmana@wht.walsallh-tr.wmids.nhs.uk

Competing interests: AS is chairman of the Research and Documentation Committee of the Muslim Council of Britain

We welcome submissions for the personal view section. These should be no more than 850 words and should be sent electronically via our website. For information on how to submit a personal view online, see http://bmj.com/cgi/content/full/325/ 7360/DC1/1 


\section{Foundation hospitals: we've been here before}

$\mathrm{H}$ ere are some headlines. "Health reforms "no cure for cash crises'." "A private hospital by any other name ..." "Unsafe hands when the heart's not in it." Here's an editorial entitled "Doctor, they're in trouble" and which starts, "Imagine the fuss if an untested and untried drug appeared on the market." Here's another: "When the NHS market crashes"-it begins, "Doctors must be uncertain whether to laugh or cry."

These headlines are the main reason that foundation hospitals are doomed. The headlines are from newspapers in $1989-90$, at the time of the Conservatives' reforms. They could be recycled. Politicians show no signs of learning the most important lesson: stop fiddling about. The difference now, 13 years on, is

Politicians show no signs of learning the most important lesson: stop fiddling about that those working in the NHS have already seen the failure of numerous other attempts to reform its structure-18 since 1980 , according to Kieran Walshe, reader in public management and director of research at Manchester Centre for Healthcare Management (Journal of the Royal Society of Medicine 2003;96:106-10).

The Labour party had 18 years in opposition to think about its favoured structure. Taking advantage of its large parliamentary majority in 1997, it could have boldly implemented that structure, bolstered by tax increases to start correcting the obvious under-investment of the previous administration. But it didn't. Instead it cowered before the right wing press, to which it attributed a large part of its electoral success. It took four years, and much rhetoric about "modernisation," before there was even proper acknowledgement that the NHS was massively underfunded and under-

Alan Milburn's tactics seem designed to outrage resourced. After more structural lurching, and an obsession with waiting list targets that has poured millions of pounds down a private sector drain, we are now presented with foundation hospitals as the saving grace of the NHS.

It is bad enough that, yet again, there is no proper evidence for health policy, for foundation hospitals being the correct medicine for the NHS. It is worse that, after six years of a Labour administration, the arguments for and against foundation hospitals echo so closely the arguments of an earlier time and of the previous administration, whose political descendants' most vocal complaint about foundation hospitals is that they don't go far enough.

What else has changed since 1990? Consultants then were merely depressed that financial imperatives were taking precedence over clinical ones. Labour's first spasms, including clinical governance and the National Institute for Clinical Excellence, were flawed but at least they stressed the clinical issue of quality. Now consultants are also angry. Clinical governance is elbowed aside as clinical priority too often takes second place to the "long waiter." Instead of making allies of consultants, managers and the government seem almost proud to make them resentful enemies. Managers see consultants as standing between them and their targets, and the government stubbornly insists that the proposed consultant contract is not up for negotiation.

Health secretary Alan Milburn's tactics seem designed to outrage: he refuses to meet the BMA but meanwhile writes consultants quasi-personal ("Dear colleague") letters. Hearing Mr Milburn ("I can't say I always agree with everything the BMA says but we have extremely good relations which I think both of us have gone out of our way to foster," BMA News Review April 1994) repeat his mantra that "most consultants do a great job for the NHS" now sounds to me like a direct threat. In the past few weeks he has made enough concessions that, had they been offered last October, would likely by now have secured an acceptable compromise. Instead his seemingly preferred local negotiations "will create divisions within the consultant body, between specialities and between colleagues"-something he must have been told during his earlier good relations with the BMA, from whose Central Consultants and Specialists Committee newsletter of March 1990 that statement was taken.

The headlines are being recycled. We've not yet seen "Secret junkets held at luxury hotels to speed NHS 'opt-outs"” (the Observer, 4 March 1990), but we have had "Foundation hospitals will kill the NHS. Don't be fooled by the rhetoric: this is about privatisation" (the Guardian, 7 May 2003). NHS staff are fed up. Kieran Walshe thinks that foundation hospitals will work-if $\mathrm{Mr}$ Milburn and his successors learn to keep their hands off. Foundation hospitals might have worked in 1997 , but we've seen too much since then. We've had too much experience. What comes next in the series "trust hospital," "foundation hospital" ...? We think it will be too soon before we find out and further reams of headed notepaper fill the recycle bins.

Neville W Goodman consultant anaesthetist, Southmead Hospital, Bristol Nev.W.Goodman@bristol.ac.uk
SOUNDINGS

\section{Reader's consent}

To help you decide whether or not to read this article, there are certain things we need to tell you. You should think about them and share them with your family, close friends, or chatroom. This will empower you to give- or withhold-your consent to reading this column.

In the past, like other journals, we relied on "implied consent." By opening the $B M J$, turning it the right way up and finding the back pages you were deemed to agree to read Soundings. This is no longer adequate.

Thanks to consumer organisations like ARMA (Action for Readers of Medical Articles), we now know what trauma may affect unprepared readers. At special risk are recently retired doctors who, never having unwrapped the $B M J$ for 30 years, go to the back pages expecting advertisements for holiday cottages. Several have recovered substantial damages for stress caused by magical realism or in your face opinions.

Please be advised, therefore, that reading Soundings may cause these unintended side effects:

Laughter Claims that "laughter is the best medicine" are not evidence based. On the contrary, it may seriously damage your health. Do not read Soundings while eating pretzels or drinking soup from those deceptively cool polystyrene cups. From January 2005 the European Reading Time Directive (ERTD) will prohibit solitary reading or reading with a full bladder.

Tears Sad stories can distress those of a sensitive disposition. We have set up a 24 hour helpline to provide counselling for people upset by these articles. This in no way affects your legal rights.

Anger Under the ERTD, before reading this column you must have undergone a course of anger management. Such courses are provided online at bmj.com/areyoulookingatme?

Drowsiness In certain circumstances Soundings may cause you to fall asleep. Therefore you must not read it while driving, operating machinery, giving (or receiving) psychotherapy, or assisting at laparoscopic surgery.

Confusion People with anhumoria (congenital inability to see the joke) may become seriously disoriented. If you have been told that you have this condition, stop reading immediately and turn to any article with "guidelines" in the title.

If you are comfortable with this information and wish to proceed, please sign below in the presence of a witness. Happy (and safe) reading!

James Owen Drife professor of obstetrics and gynaecology, Leeds 